\title{
PrevalenceAnd Socio-Demographic Factors Associated With Depression Among Patients With Tuberculosis Attending TB Clinic of Butabika National Referral Mental Hospital.
}

\author{
Ellen Nagaddya Kisemboa \\ a School of Psychiatric Cinical Officers Butabika
}

\begin{abstract}
\end{abstract}

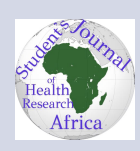

Background:

Depression is a major cause of the global disease burden, affecting an estimated 350-400 million people worldwide. This makes it the largest contributor to Years Lived with Disability (YLDs) globally

Methodology:

It was a descriptive cross-sectional study with an analytic component in which 82 patients already diagnosed with TB were recruited for the study using stratified sampling technique and convenient sampling technique. PHQ-9 was used to assess for presence and severity of depression, a score above 9 was considered to be depressed. Socio-demographic questionnaire was used to obtain the socio-demographic characteristics. Data entry and analysis was done using SPSS $23^{r d}$ version, Chi-square test and T-test were used to find associations of socio-demographic factors to depression.

Results:

The prevalence of depression was $54.9 \%$, out of whom $22.2 \%, 66.7 \%$ and $11.1 \%$ had mild, moderate and severe depression respectively. Depression was more prevalent in patients from a nuclear family (34.1\%), in age group of 31 to 60 years (32.9\%), treatment duration of 1 month (31.7\%), among the females (29.3\%), and patients who were unemployed $28 \%$.

\section{Conclusion:}

In conclusion, the prevalence of depression (54.9\%) in TB patients is high, with most patients moderately depressed and this could be associated with multiple socio-demographic factors like being female, age of 30-60 years, unemployment, low education level, being in the intensive phase of TB treatment, HIV and TB co-morbidity.

Recommendations : ${ }^{a}$

There is need for integration of mental health services into TB treatment to ensure routine screening, early diagnosis and treatment of mental disorders like depression to prevent their co-morbidity with TB, which often has negative treatment outcomes. There is need to carry out more research on depression in patients with TB to widen knowledge about this problem.

\footnotetext{
${ }^{a}$ submitted:18th $/ 9 / 2021$

accepted: 23rd/9/2021 email: nagaddyaellen@gmail.com
}

\section{Background}

Depression disturbed sleep and/or appetite, and poor concentration (APA, Depression is a mood 
disorder that presents with depressed mood, loss of interest, feelings of guilt, or low self-worth 2013).

Depression is a major cause of the global disease burden, affecting an estimated 350-400 million people worldwide. This makes it the largest contributor to Years Lived with Disability (YLDs) globally (Marcus et al., 2012). A study carried out by WHO in 2012 in 17 countries revealed that 1 in 20 people reported having depression (Marcus et al., 2012). Among patients with chronic physical illnesses like cancer, hypertension, TB, the prevalence is between 10-20\% (Katon, et al., 2007).

Mycobacterium tuberculosis is the bacteria that causes the infection called tuberculosis. It's considered to be one of the most globally deadliest and transmissible diseases (WHO, 2016). TB is a major global public health problem, mostly in developing and underdeveloped countries and globally it's responsible for more than 3 million deaths each year and is one of the evading causes of mortality worldwide (Sulehri et al., 2010). WHO reported that a third of the world population (approximately 2 billion people) is infected with TB and that there are about 8-10 million new active cases every year. There are 8.8 million new cases of TB in 2005, the highest being in Africa (28\% of all TB cases) and half of all the new cases in 6 Asian countries namely Bangladesh, China, Indian, Indonesia, Pakistan, and Philippines (Husian, 2008).

TB is a chronic disease and there are high chances of the existence of various psychological problems in TB patients. Individuals with TB often have co-morbid depression that often requires frequent hospitalizations thus posing great challenges to the care of such patients (Ige et al., 2011).

Depression and TB are important public health concerns that contributed 2.5 and $2 \%$ respectively of Disability Adjusted Life Years (DALYs) worldwide in 2010 (Murray et al., 2013). Depression is 3 to 6 times more common in patients with TB compared to patients without TB (Sweetland et al., 2014).

Globally in 2014, 9.6 million people developed TB and 3.3\% were multi-drug-resistant tuberculosis (MDR-TB) cases with more than 1.5 million cases occurring in sub-Saharan Africa each year(Zumla, et al., 2015).

Evidence from cross-sectional studies done in African hospitals indicates a very high prevalence of co-morbid depression among patients with TB ranging between $10-52 \%$, with the one study in Nigeria reporting it at $27.7 \%$ (Deribew et al., 2010).
A study done in Uganda at Mulago hospital on the prevalence of depressive symptoms among medically ill patients found that $25 \%$ of the patients had chest infections including TB and 35\% of the medically ill patients had a depressive illness (Katorogo, 2006)

\section{METHODOLOGY}

The study was a descriptive cross-sectional study and employed both quantitative and qualitative research methods. A Cross-sectional study is an observational study that collects data from the whole study population at a single point in time to examine the relationship between variables. It is a combination of both qualitative and quantitative approaches.

A qualitative approach was used to get underlying opinions, feelings, and thoughts from respondents. This approach was essential where the purpose was to discover underlying patterns of responses as a depth interview technique was used to collect data.

A quantitative research design was used in this study. This design was used to collect numerical data. This method was useful in establishing relationships and differences between variables within the sample. This approach also helped us analyze qualitative data acquired.

\section{Study setting and rationale}

The study was carried out at TB clinic in Butabika National Referral Mental Hospital (BNRMH), a governmental hospital located in Butabika, the southeastern part of the city, in Nakawa division, adjacent to the northern shores of Lake Victoria, Kampala district, Buganda region. The location is approximately 12 kilometers by road, east of Kampala's central business center. It is located on plot 2 Kirombe-Butabika road. The coordinates of Butabika Hospital are 0018'57.0" N, 32039'33.0" E. (Latitude: 0.315845; Longitude: 32.659160) (Globefeed.com, 2014). Butabika hospital is a public psychiatric hospital with a capacity of 550 patients though it houses about 700-800 patients at any one time. It provides expert management for patients with mental, neurological, and substance use problems as inpatients inwards. It also provides outpatient department services where it sees about 350 clients per day in both general and mental health clinics. The hospital also has different departments such as Psychology, Occupational ther- 
apy, Community health, Finance, and administrative departments, Alcohol and Drugs Unit, Private Unit, Children's department, and Outpatient department comprises of different clinics such as Mental health clinic, Orthopedic clinic, Eye clinic, ART and TB clinic, Maternal and Child health care among others. (MOH-Uganda, 2015) BNMRH is headed by the Executive director, deputized by a Senior Consultant Psychiatrist who is the Clinical head; Nursing departments are headed by Assistant Commissioner Nursing, followed by Senior Principal Nursing officer, Principal Nursing Officer, and Senior Nursing Officers who are the wards in-charges and deputized by nursing officers. BNMRH is also a Research and Training institute for different Institutions such as Makerere University, Butabika School of Psychiatric Clinical Officers, and Butabika School of Psychiatric Nursing among others. The study intends to be carried out at the Infectious Disease Clinic (IDC) of Butabika Hospital. Butabika hospital was chosen for the convenience of the researcher and IDC has patients with TB enough for the sample space.

\section{Study population}

The study included male and female patients with TB under the care and considered those who were under care for 1 month, 3 months, and 6 months. According to the TB clinic register of 2018, the clinic had 107 patients among which 28 were at 1 month, 57 at 3 months, and 22 at 6 months.

\section{Sample size determination}

The sample size was determined using KishLeslie's formula for survey samples (Glenn, 1992) where;

no $=$ sample size required

$\mathbf{p}=$ estimated prevalence of depression among TB patients in Uganda is 35\% (Katorogo, 2006).

$\mathbf{q}=(\mathbf{1}-\mathbf{p})$ and is the probability of not having depression

$\mathbf{z}=$ normal standard deviation at $95 \%$ confidence interval corresponding to 1.96

$\mathbf{e}=$ absolute error between the estimated and true population prevalence is $5 \%$

The calculated sample size $=$

$\mathrm{n} \mathbf{0}=\mathbf{3 5 0 . 0}$

To get the appropriate sample size for a study on 107 TB patients approximated to be in care at TB clinic in Butabika National referral hospital in 2018, a finite population correction for proportions formula was used as below to calculate the sample size (Glenn, 1992) Where $\mathbf{n}=$ proportionate sample size required, $\mathbf{N}=$ Population of patients with TB which is approximately 107 .

(Rounded off to the nearest tens)

Convenient sample size of 82respondents was interviewed.

\section{Sampling procedure}

The study used a stratified sampling technique. In selecting proportional stratified samples, the population size of each stratum was multiplied by the required (total) sample size and divided by the total population i.e. Where the strata were divided as follows: At one month, $=21$, Three months $=44$, and Six months $=17$ respondents.

This reduced the sampling errors because variation between the strata was not incorporated in the calculation of the sampling errors. After acquiring the required sample size in each stratum, the researcher used a non-random sampling technique specifically the convenient sampling method since the respondents could not be put in a cluster at a single time.

\section{Inclusion criteria:}

The study included Patients on treatment for TB who were in care for 1 month, 3 months, and 6 months both male and female in the TB clinic of Butabika National Referral Mental Hospital.

\section{Definition of variables}

The Independent variables included the sociodemographic variables of patients with TB associated with depression for example; age, sex, duration of stay in care, financial status, and co-morbid chronic illness, among others. The dependent variable of the study was the prevalence of depression among patients with TB.

\section{Research instruments}

The interview-guided questionnaire was used to collect data. The questionnaire method was used because it would generate information within a short time. The open-ended questions helped to generate the wide views of the respondents and closed-ended questions gave precise answers. A socio-demographic questionnaire was used to obtain data on the socio-demographic characteristics. Depression was assessed using the Patients' Health Questionnaire ninth item (PHQ-9) and it was also used to rate the severity of depression. The PHQ-9 has 9 items used to identify depression with acceptable levels of sensitivity and specificity. A validation study in Uganda showed that the PHQ-9 has reasonable sensitivity (91.6\%) and specificity(81.2\%), accuracy in classifying classes of depression, is eas- 
ily implemented by health workers and is a useful screening tool in a primary care setting (Akena, et al., 2013). The questionnaire has a maximum score of 27 and a minimum score of 0 [10-15=mild, 16$20=$ moderate,$>20=$ severe depression), individuals who score $>9$ are considered to have depression. In this study, the researcher used the English version of the questionnaire.

\section{Data collection procedure}

After receiving the approval letter from Butabika School of Psychiatric Clinical Officers, the letter was forwarded to Butabika Hospital Research Ethics Committee seeking permission to collect data. After approval by the REC of Butabika Hospital, the researcher approached patients after being introduced by the health worker on duty to request them to participate in the study. After obtaining consent, respondents were interviewed by the researcher immediately. The researcher then checked the questionnaires well if all questions were answered before leaving the respondents. The questionnaires were then kept safely until all the 82 respondents were achieved.

\section{Data management}

The filled questionnaires were kept safely in the lockable cupboard and the key was kept by the researcher. Data were coded, entered into SPSS, and kept on flash disks in soft copy to allow revisiting in case of any reference. After analysis and dissemination of results, the researcher cleaned data and consent forms immediately to keep the respondents anonymous.

\section{Data analysis}

Data entered in SPSS was analyzed using the Statistical Package of Social Sciences and presented in form of tables, graphs, and pie charts using frequencies and numbers. The study also determined the associated factors using Chi-square and t-test. Qualitative data was analyzed using content analysis and responses were categorized according to a common meaning, after responses were also coded, and also analyzed quantitatively with the numerical presentation.

\section{Ethical consideration}

The researcher presented an introductory letter from Butabika School of Psychiatric Clinical Officers introducing the researcher to the administration of Butabika National Referral Mental Hospital seeking permission to carry out the study. The administration of the Hospital gave the researcher an approval letter allowing her to collect data. The study com- menced after explaining the objectives of the study to participants who then voluntarily consented to participate in the study. Respondents were assured of maximum confidentiality of all the information given and numbers instead of names were used to keep respondents' identity anonymous. All consenting participants signed the consent forms, while illiterate individuals would signify consent by use of a thumbprint, witnessed by a relative or caregiver of that participant. Participants who declined consent were not prejudicially treated and all their care was uninterrupted. The researcher abode by the guidelines given by the Butabika Hospital Research Ethics Committee (BHREC) for the protection of patients and the committee was consulted for dissemination of results.

\section{The study limitations}

1. The researcher encountered limitations such as; limited time since the TB clinic was receiving very few patients weekly and this made the researcher extend the data collection period. 2 . The study also used a small sample size and thus cannot be generalized to the entire country due to ethnic minority groups and regional differences in standards of living and health care.

Dissemination of results: The study results were disseminated to the following: Uganda Allied Health Examinations Board, Butabika National Referral Mental Hospital, Butabika School of Psychiatric Clinical Officers, Research supervisor

\section{RESULTS}

\section{Socio-demographic characteristics among respondents:}

Data was collected from 82 respondents aged 18 years and above, with TB. There socio-demographic characteristics are shown in the table below

From the table above; majority $41(50 \%)$ were 31 to 60 years and male 51(62.2\%); most 31(37.8\%) were Catholic, had attained secondary level of education $37(45.1 \%)$, were staying in a nuclear family 53(64.6\%), single 34(41.5\%) and employed 43(52.4\%).

From table above; most 43(52.4\%) had stayed on anti TB treatment for 1 month, HIV was the most reported chronic physical illness $27(32.9 \%)$, $21(25.6 \%)$ were on treatment for mental illness and 
Table 1. shows socio-demographic characteristics of the respondents

\begin{tabular}{|c|c|c|c|}
\hline \multirow[t]{2}{*}{ Category } & Variable & Frequency $n=82$ & Percentage (\%) \\
\hline & $18-30$ years & 38 & 46.3 \\
\hline \multirow[t]{2}{*}{ Ages } & $31-60$ years & 41 & 50.0 \\
\hline & Above 60 years & 3 & 3.7 \\
\hline \multirow{4}{*}{ Sex } & Male & 51 & 62.2 \\
\hline & Female & 31 & 37.8 \\
\hline & Protestants & 16 & 19.5 \\
\hline & Catholics & 31 & 37.8 \\
\hline \multirow[t]{4}{*}{ Religion } & Muslims & 7 & 8.5 \\
\hline & Born again & 27 & 32.9 \\
\hline & SDA & 1 & 1.2 \\
\hline & No formal education & 6 & 7.3 \\
\hline \multirow{3}{*}{ Level of education } & Primary & 32 & 39.0 \\
\hline & Secondary & 37 & 45.1 \\
\hline & Tertiary/university & 7 & 8.5 \\
\hline In what type of family do you & Nuclear family & 53 & 64.6 \\
\hline \multirow[t]{2}{*}{ stay } & Extended family & 29 & 35.4 \\
\hline & Married/cohabiting & 23 & 28.0 \\
\hline \multirow{4}{*}{ Marital status } & Widowed & 2 & 2.4 \\
\hline & Separated & 23 & 28.0 \\
\hline & Single & 34 & 41.5 \\
\hline & Unemployed & 30 & 36.6 \\
\hline \multirow[t]{2}{*}{ Employment } & Employed & 43 & 52.4 \\
\hline & Student & 9 & 11.0 \\
\hline
\end{tabular}

Table 2. shows the other illness related socio-demographic characteristics

\begin{tabular}{llll}
\hline Category & Variable & Frequency $n=2$ & Percentage (\%) \\
Duration on anti-TB & 1 month & 43 & 52.4 \\
treatment & 3 months & 23 & 28.0 \\
Have another chronic & 6 Months & 16 & 19.5 \\
medical illness & Yes & 33 & 40.2 \\
& No & 49 & 59.8 \\
If yes, please specify & HIV & 27 & 32.9 \\
& Hypertension & 3 & 3.7 \\
Receiving treatment for any & None & 52 & 63.4 \\
mental illness & No & 21 & 25.6 \\
History of depression in the & Yes & 61 & 74.4 \\
family & No & 19 & 23.2 \\
\hline
\end{tabular}

19(23.2\%) had a family member who was suffering from depression.

\subsection{Prevalence of depression among respondents}

Figure 1: shows the prevalence of depression among respondents.

From figure above; the prevalence of depression was 45(54.9\%) among respondents.
Figure 2: shows the prevalence of depression according to duration on treatment among respondents

From the figure above; most 26(31.7\%) of those who had been on anti-TB treatment for 1 month had depression and only $8(9.8 \%)$ of those who had been on treatment for 3 months had depression. 


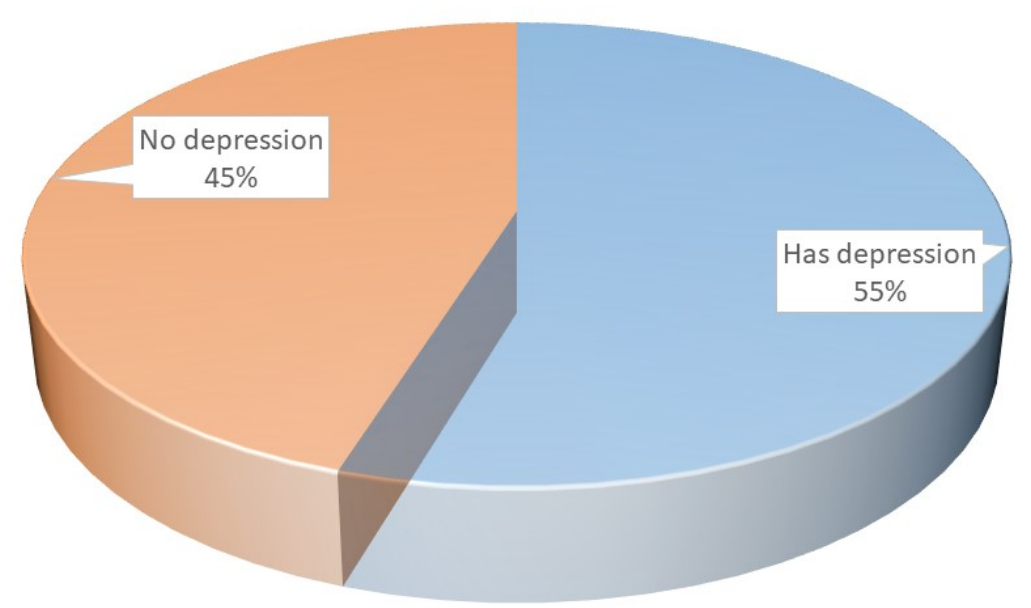

Chart 1. shows the prevalence of depression among respondents.

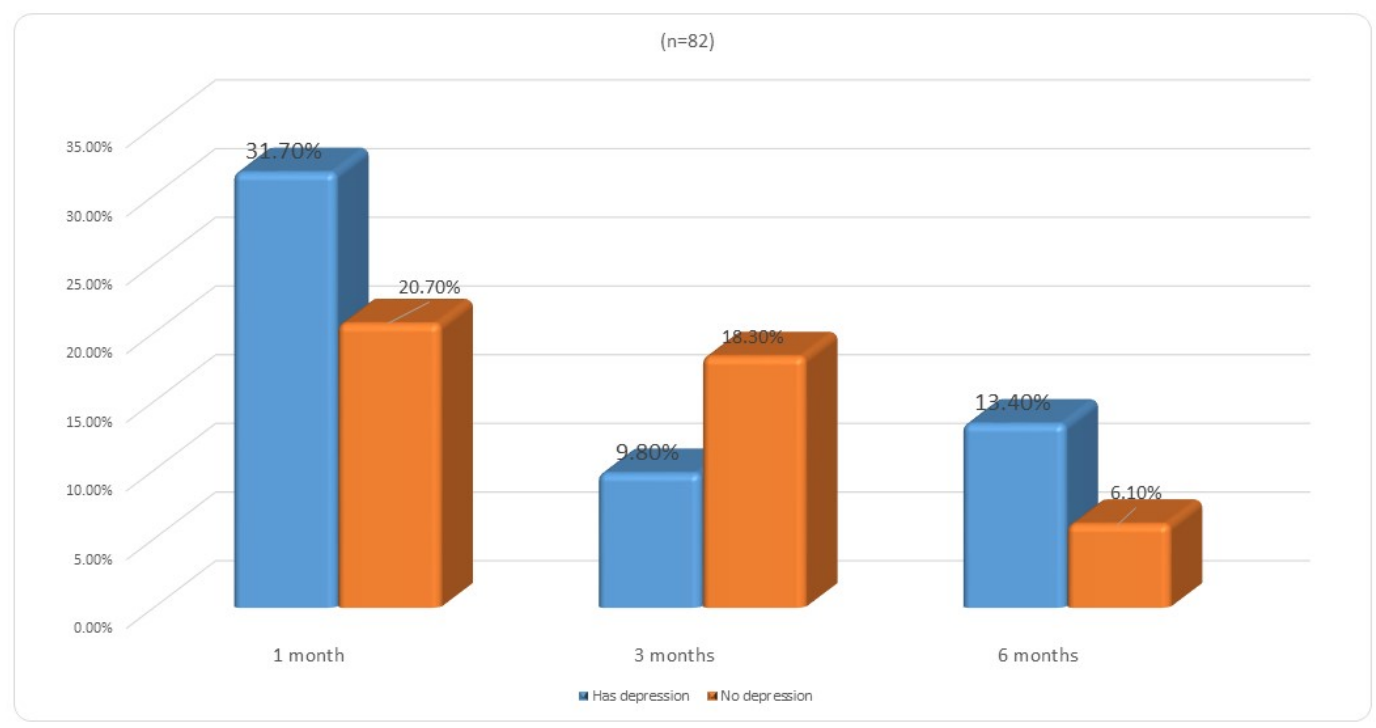

Chart 2. shows the prevalence of depression according to duration on treatment among respondents 


\section{Severity of depression}

Figure 3: shows the severity of depression among respondents who had depression.

From the figure above; majority 30(66.7\%) had moderate depression while 5(11.1\%) had mild depression.

\section{Socio-demographic characteristics associated with depression among respondents}

From table above; majority of respondents who had depression were 31 to 60 years $32.9 \%$, female $29.3 \%$, born again $23.2 \%$, had attained primary level of education $22 \%$, were staying in a nuclear family $34.1 \%$, single $20.7 \%$ and unemployed $28 \%$.

\section{DISCUSSION}

\section{Prevalence of depression among respondents}

This study set out to determine the prevalence of and socio-demographic factors associated with depression among patients with TB in Butabika Hospital. From the data analysis, the prevalence of depression was found to be $54.9 \%$. This suggests a high burden of depressive illness among patients with TB as compared to a prevalence of 5.2 $-12.9 \%$ in the general population (Ainaitwe., 2018). This prevalence is probably because of the chronic nature of TB, the disease is stigmatizing, patients worry about the disease outcomes, distorted social and work relationships, etc. The findings are similar to another study carried out in Pakistan that 56\% of tuberculosis patients had moderate to severe depression using PHQ-9 (Amreen, Rizvi., 2016).

Contrary to this study, Alinaitwe (2018) in Mulago hospital reported a lower prevalence of $23.7 \%$ using the MINI. However, this difference may have been due to the different tools to collect data and Alinaitwe used a relatively larger population size.

In contrast to the current study, Amuthon (2011) discovered a higher prevalence of $63 \%$ in Kenya using the BDI. The BDI tool results are considerably higher because it's a screening tool for depression and not a diagnostic tool thus exaggerates results.

\section{The severity of depression.}

Findings indicated varying levels of severity among the 45 depressed patients. 30(66.7\%) were moderately depressed, 10(22.2\%) were mildly depressed and $5(11.1 \%)$ were severely depressed. The difference in severity is probably due to differences in severity of symptoms, in social support, in economic status, education levels, different effects of the disease on one's personal life and individual characteristics as some people are more prone to severe depression, co-morbidity with HIV were also associated with severe depression, being in the intensive phase of treatment was associated with mild and moderate depression. Contrary to this study, results from a study in Pakistan showed there were less moderately (45.8\%) and mildly (16.7\%) depressed patients as compared to this study (66.7\% and $22.2 \%$ respectively), and this huge difference could be due to use of different data collection tools and the other study had only in patients.

Socio-demographic characteristics associated with depression among respondents

Results of the study showed that $32.9 \%$ of the patients with depression were aged 30-60 years; this is possibly due to stigma, and compromised social and work relationships that are associated with TB in this age group. This is in line with findings of another study that depression among TB patients was common in the elderly (Ahmed, et al., 2016) and Ambaw et al., (2017) added that increasing age was reported as a significant factor in developing depression, in that for every 14 years increase in age, the risk of having depression increases by $19 \%$ (Ambaw et al., 2017).

The prevalence of depression was also significantly associated with the duration of anti TB treatment; $31.7 \%$ of depressed respondents had been on treatment for 1 month and only $9.8 \%$ of those who had been on treatment for 3 months had depression; this implies that depression resolves with time as one gets anti TB treatment. Contrary to the present study, Ambaw Rosie et al., (2018) reported a higher prevalence rate $53.3 \%$ at baseline following diagnosis which may have been a drastic reaction to the diagnosis of a stigmatizing disease but the same study discovered similar results that the prevalence of depression was $7.8 \%$ by 2 months and 6 months. This could be because the symptoms of tuberculosis tend to be prominent in the intensive phase compared to the continuation phase of TB treatment. The coughing, chest pain, night sweats, and fevers probably affect an individual's quality of life in terms of sleep, appetite, 


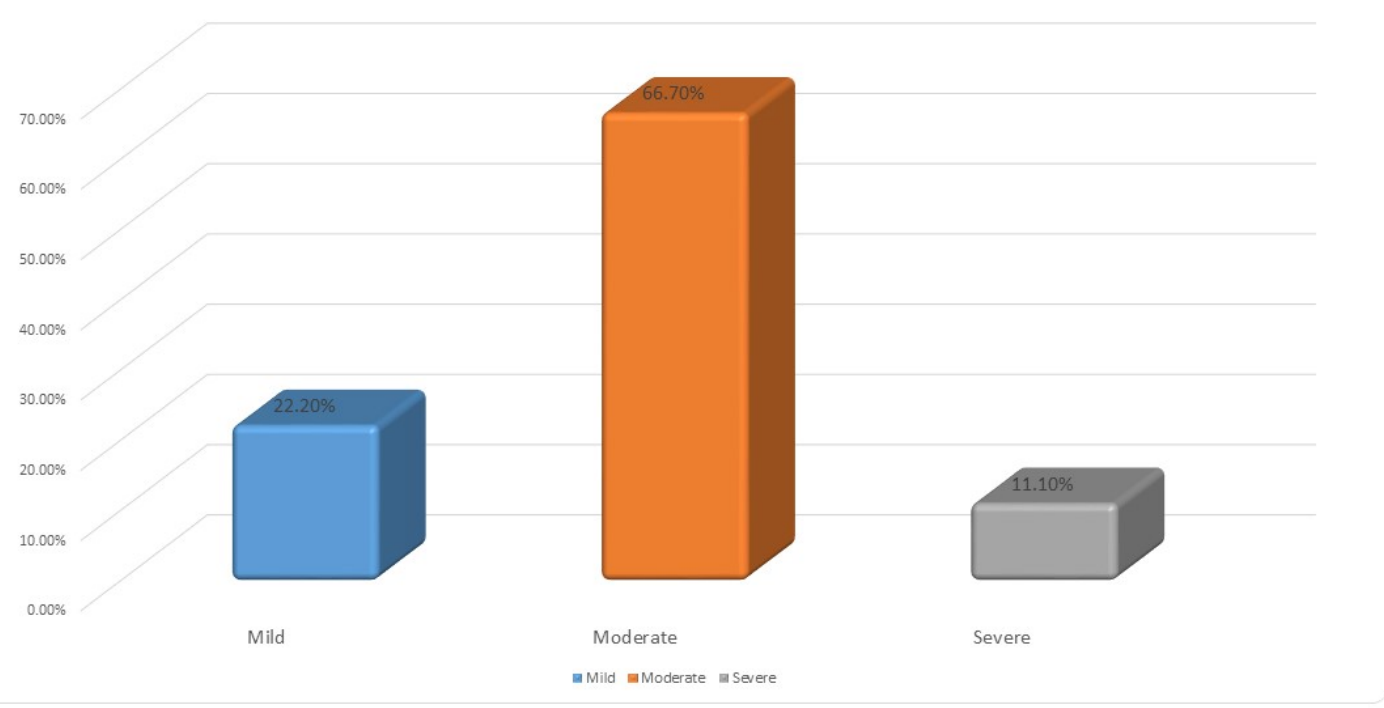

Chart 3. shows the severity of depression among respondents who had depression.

Table 3. shows the bi-variate analysis of socio-demographic characteristics significantly associated with depression using chi-square test.

\begin{tabular}{|c|c|c|c|c|c|}
\hline \multirow[t]{3}{*}{ Category } & \multirow[t]{3}{*}{ Variable } & \multicolumn{4}{|c|}{$\begin{array}{l}\text { Prevalence of depression using patient questionnaire-ninth } \\
\text { item }\end{array}$} \\
\hline & & \multicolumn{2}{|c|}{ Has Depression } & \multicolumn{2}{|c|}{ No depression } \\
\hline & & $\mathrm{F}$ & $\%$ & $f$ & $\%$ \\
\hline & $18-30$ years & 15 & 18.3 & 23 & 28.0 \\
\hline \multirow[t]{2}{*}{ Age } & $31-60$ years & 27 & 32.9 & 14 & 17.1 \\
\hline & Above 60 years & 3 & 3.7 & 0 & 0.0 \\
\hline \multirow{2}{*}{ Sex } & Male & 21 & 25.6 & 30 & 36.6 \\
\hline & Female & 24 & 29.3 & 7 & 8.5 \\
\hline \multirow{5}{*}{ Religion } & Protestants & 13 & 15.9 & 3 & 3.7 \\
\hline & Catholics & 9 & 11.0 & 22 & 26.8 \\
\hline & Muslims & 3 & 3.7 & 4 & 4.9 \\
\hline & Born again & 19 & 23.2 & 8 & 9.8 \\
\hline & SDA & 1 & 1.2 & 0 & 0.0 \\
\hline \multirow{4}{*}{$\begin{array}{l}\text { Level of } \\
\text { education }\end{array}$} & No formal education & 6 & 7.3 & 0 & 0.0 \\
\hline & Primary & 18 & 22.0 & 14 & 17.1 \\
\hline & Secondary & 16 & 19.5 & 21 & 25.6 \\
\hline & Tertiary/university & 5 & 6.1 & 2 & 2.4 \\
\hline \multirow{3}{*}{$\begin{array}{l}\text { In what type of } \\
\text { family do you } \\
\text { stay }\end{array}$} & Nuclear family & 28 & 34.1 & 25 & 30.5 \\
\hline & Extended family & 17 & 20.7 & 12 & 14.6 \\
\hline & Married/cohabiting & 12 & 14.6 & 11 & 13.4 \\
\hline \multirow{3}{*}{ Marital status } & Widowed & 1 & 1.2 & 1 & 1.2 \\
\hline & Separated & 15 & 18.3 & 8 & 9.8 \\
\hline & Single & 17 & 20.7 & 17 & 20.7 \\
\hline \multirow{3}{*}{ Employment } & Unemployed & 23 & 28.0 & 7 & 8.5 \\
\hline & Employed & 19 & 23.2 & 24 & 29.3 \\
\hline & Student & 3 & 3.7 & 6 & 7.3 \\
\hline
\end{tabular}


and self-esteem hence more chances of one being depressed. However, depression can also increase the severity of physical symptoms of TB (APA 2013, Ambaw et al., 2017).

Participants with no employment were more likely to have a depressive illness (28\%) than those with employment (23.2\%). Unemployment affects one's socioeconomic status and this increases the individual's risk of having a depressive illness, it also compromises access to quality health care. Similar findings are reflected in the study carried out by Issa et al., (2009) at a University teaching hospital outpatient clinic in Nigeria. Low socioeconomic status has been implicated in many studies as a risk factor for depression (Alinaitwe., 2018).

$34.1 \%$ of respondents with depression were staying in a nuclear family; this may be due to compromised social support in face of a stigmatizing disease such as TB. This was supported by Olusoji \& Olufolahan (2011) that nuclear family and lack of socio-economic support (Argiro et al., 2013) was associated with depression among TB patients.

Gender distributions were inclined more to the female as $29.3 \%$ of the depressed patients were all female; similar to this study, being female was also shown to be associated with a higher prevalence of depression in patients with TB and this has been attributed to the association between female hormonal factors and depression(Kehbila, et al., 2016). The association between depressive illness and females could be due to female hormones like estrogen and also social roles of women in society (Ahuja 2011).

The study revealed that $23.2 \%$ of depressed respondents were of the born-again religion. It is suspected that many patients with depression or no hope end up joining the born-again religion for companionship and hope for special healing because born-again worship is believed to be good therapy for patients with depression. However, there is no literature published on a religious basis among TB patients with depression.

Respondents at the primary level of education had the highest prevalence of depression (22\%); a low level of education has been associated with ignorance of transmission about TB hence can easily be exposed to $T B$, and may not be able to recognize symptoms of TB. A low level of education has also been associated with unemployment (28\%) and low standards of living which may not be supportive enough for a person with TB (Aniebue et al., 2007). A higher level of education leads to better income and access to a wide range of health services, hence better (mental) health outcomes (Ambaw et al., 2017). Level of education was independently associated with depressive illness even at multivariate analysis (Alinaitwe., 2018).

Being single, or separated were associated with a higher prevalence of depression than other counterparts; several studies discovered that being single was significantly associated with depression among TB patients (Aniebue et al., 2007), unmarried (Olusoji et al., 2011) and widow(er) (Issa, et al., 2009). Being single or widowed is greatly associated with a lack of supportive care and motivation to complete treatment regimen, difficulty in finding a partner, and loneliness hence depression.

The study revealed that other co-morbidities like HIV/AIDS were associated with a high prevalence of depression, and this could be due to the stigma from both TB and HIV, the pill burden, and the debilitating effects of both TB and HIV. This is similar to studies by Kehbila et al., (2016), Duko et al., (2015), and Ambaw et al., (2017) which have all shown a significant association between TB and HIV/AIDS co-morbidity with depressive illness.

\section{Conclusion}

In conclusion, the prevalence of depression (54.9\%) in TB patients is high, with most patients moderately depressed and this could be associated with multiple socio-demographic factors like being female, age of 30-60 years, being single or separated, unemployment, low education level, being in the intensive phase of TB treatment, family history of depressive illness, HIV and TB co-morbidity.

\section{Recommendations}

1. The ministry of health should publish and equip all TB clinics with guidelines to screen and treat depression and other common mental disorders among TB patients, to prevent co-morbidity of such disorders with TB. 2 . The ministry of health together with other research bodies needs to research other regions of the country using a larger sample size to estimate the actual prevalence of depression among TB patients and to identify more risk factors for depression in the TB patients. 3 . There is a need to train general health workers in mental health such that they can identify those at risk of developing mental disorders and refer them for full assessment as early as possible.

4. Health workers in TB clinics ought to address other psycho-social challenges faced by TB patients 
to prevent patients from getting depressed, as well as mass sensitization of the public about TB to address social stressors towards TB patients.

\section{ACKNOWLEDGEMENT}

Foremost thanks go to the Almighty God for taking me through all the struggles to my success.

My thanks also go to the entire administration of the school of psychiatric clinical officers Butabika for the help they rendered to me when approached.

Cordially I send my appreciation to the administration of Butabika National Referral Mental Hospital, for having allowed me to collect data.

I also thank my supervisor Mr. Kasozi Corlder for his guidance in the supervision of this work.

My appreciation further goes to the Head and Staff of the Tuberculosis unit in Butabika Hospital for their support in the proposal development and data collection process.

My sincere thanks also go to my friends, most especially Mr. Magulu Jolly Davidson, Ms. Nayiga Rose, Ms. Nalubulwa Alice, Ms. Lutta Daphine, Mr. Nsubuga Reagan, Mr. Ziryawulawo Ibrahim, and the rest of my classmates for helping me throughout the research process.

My humble appreciation goes to the patients of tuberculosis who gave in their time to interact with me during the study.

\section{LIST OF ABBREVIATIONS}

AIDS: Acquired Immune Deficiency Syndrome BDI: Beck's Depression Inventory BNRMH: Butabika National Referral Mental Hospital

DALYs: Disability Adjusted Life Years

DOT: Directly Observed Therapy

DSM: Diagnostic and Statistical Manual for Mental disorders

GHQ-12: Genera Health Questionnaire twelfth item.

HADS: Hospital Anxiety and Depression Scale

HIV: Human Immunodeficiency Virus

MDR-TB Multi-Drug Resistant Tuberculosis

$\mathrm{MOH}$ : Ministry Of Health

PHQ-9: Patient Health Questionnaire ninth Item

SPSS: Statistical Package of Social Sciences

TB: Tuberculosis

WHO: World Health Organization

YLDs: Years Leaved with Disability

\section{A References:}

1. Ahmed, M. M., Mahpara, M.,\& Arslan, Z. (2016). Depression in Tuberculosis patients and its relationship to socio demographic factors. Journals of Rwapindi Medical College. Pg 296-299.

2. Ahuja N. A short textbook of psychiatry. 7th ed. New Delhi: Jaypee Brothers Medical Publishers; 2011. https://doi.org/10.5005/jp/books/11464

3. Alinaitwe, R. (2018). Prevalence and factors associated with depressive illness in patients with tuberculosis in Mulago hospital.

4. Ambaw, F., Mayston, R., Hanlon, C., \& Alem, A. (2017). Burden and presentation of depression of depression among newly diagnosed individuals with TB in primary care settings in Ethiopia. BMC psychiatry. Pg 57 https://doi.org/10.1186/s12888-0 17-1231-4 PMid:28173847 PMCid:PMC5297050

5. Ambaw, F., Mayston, R., Hanlon, C., Alem, A., \& Medhin, G. (2018). Untreated depression and tuberculosis treatment outcomes, quality of life and disability, Ethiopia.Bulletin of World Health Organisation. https://doi.org/10.2471/BLT.17.19265 8 PMid:29695881 PMCid:PMC5872008

6. Amreen., \& Rizvi, N. (2016). Frequency of depression and anxiety among TB patients. Journal of tuberculosis research. Pg 183-190. https://doi.or g/10.4236/jtr.2016.44021

7. Amuthon, N. (2011). Study on prevalence of depression among TB patients in district hospital clinic -Kenya. Nairobi University Medical Journal.

8. Aniebue, P. N., \& Okonkwo, K. O. B. (2007). Prevalence of depressive symptoms amongst pulmonary tuberculosis patients at the University of Nigeria Teaching Hospital, Enugu. Journal of College of Medicine. Pg 120-124.

9. Argiro, P., Dionisios, B., Georgios, M., \& Athanasios, T. A. (2013). Psychiatry morbidity and other factors affecting treatment adherence in pulmonary tuberculosis patients Tuberculosis Research and Treatment. https://doi.org/10.1155/201 3/489865 PMid:23691305 PMCid:PMC3649695

10. Deribew, A., Tesfaye, M., Hailmichael, Y., Apers, L., Abebe, G., Duchateau, L., \& Colebunders, R. (2010). Common mental disorders in TB/HIV co-infected patients in Ethiopia. BMC Infectious Diseases. Pg 1. https://doi.org/10.1186/1471-233410-201 PMid:20618942 PMCid:PMC2911449

11. Duko, B., Gebeyehu, A., \&Ayano G. (2015). Prevalence and correlates of depression and anxiety among patients with tuberculosis at Wolaita- 
sodo university hospital and Sodo health center South Ethiopia cross sectional study. BMC Psychiatry. Pg 15-214. https://doi.org/10.1186/s12888-0150598-3 PMid:26370894 PMCid:PMC4570612

12. Issa, B. A., Yusuf, A. D., \&Kuranga, S. I. (2009). Depression co morbidity among patients with tuberculosis in a university teaching hospital outpatient clinic in Nigeria. Mental Health Fam Med. Pg 133-138.

13. Katon, W. J., Lin, E. H., \& Kroenke, K. (2007). The association of depression and anxiety with medical symptom burden in patients with chronic medical illness. General hospital psychiatry,. General Hospital Psychiatry. Pg 147155. https://doi.org/10.1016/j.genhosppsych.2006 .11.005 PMid:17336664

14. Katorogo. (2006). Prevalence of depressive symptoms among medically ill patients on the medical wards in Mulago hospital; research project for diploma in Clinical Psychiatry, Makerere University) (not published).

15. Kehbila, J., Ekabe, C. J., Aminde, L. N., Noubiap, J. J. N., Fon, P. N., \& Monekosso, G. L. (2016). Prevalence and correlates of depressive symptoms in adult patients with pulmonary tuberculosis in the Southwest Region of Cameroon. Infectious Diseases of Poverty. Pg 1. https://doi.org /10.1186/s40249-016-0145-6 PMid:27268138 PMCid:PMC4895984

16. Marcus, M., Yasamy, M. T., VanOmmeren, M., Chisholm, D., \&Saxena, S. (2012). Depression: A globalpublic health concern. WHO Department of Mental Health and Substance Abuse. Pg 6-8. https: //doi.org/10.1037/e517532013-004

17. McFarlane, J., Nava, A., Heidi, G.,\& Maddoux, J. (2014).https://www.merriam-webster.com/dictio nary/co-morbid. Accessed 24th Feb

18. Murray, C. J., Vos, T., Lozano, R., Naghavi, M., Flaxman, A. D., Michaud, C., ... \& Aboyans, V. (2013). Disability-adjusted life years (DALYs) for 291 diseases and injuries in 21 regions, 1990-2010: a systematic analysis for the Global Burden of Disease Study 2010. The Lancet. Pg 380. https://doi.or g/10.1016/S0140-6736(12)61690-0

19. Olusoji, I. M., \& Olufolaham, V. L. (2011). Prevalence of depression in tuberculosis patients in comparison with non-tuberculosis family contacts visiting the DOTS clinic in a Nigerian tertiary care hospital and its correlation with diseasepattern. Mental Health in Family Medicine. Pg 235-241
20. Sulehri, M. A., Dugar, I. A., Sohail, H., \&Mehdi, Z. (2010). Prevalence of depression among tuberculosis patients. Annals of Punjab Medical College. Pg 133-137.

21. Sweetland, A., Oquendo, M., Wickramaratne, P., Weissman, M., \& Wainberg, M. (2014). Depression: a silent driver of the global tuberculosis epidemic. World Psychiatry. Pg 325-326. https:/ /doi.org/10.1002/wps.20134 PMid:25273311 PMCid:PMC4219079

22. Thomas, B. E., Shanmugam, P., Malaisamy, M., Ovung, S., Suresh, C., Subbaraman, R., ... \&Nagarajan, K. (2016). Psycho-socio-economic issues challenging multidrug resistant 38 tuberculosis patients: a systematic review. PloS One. Pg 1. https://doi.org/10.1371/journal.pone.0147397 PMid:26807933 PMCid:PMC4726571

23. WHO. (2014). Fact sheet on Tuberculosis. Geneva

24. WHO. (2015). Use of high burden countries lists for TB by WHO in the post 2015 era. WHO/HTM/TB. Geneva.

25. WHO. (2016). Global tubercuosis report. Geneva

26. Zumla, A., George, A., Sharma, V., Herbert, R. H. N., Ofllton, B. M., Oxley, A., \& Oliver, M. (2015). The WHO 2014 global tuberculosis report-further to go. The Lancet Global Health. Pg 10-12. https:// doi.org/10.1016/S2214-109X(14)70361-4 